\title{
MicroRNA-674-5p induced by HIF-1a targets XBP-1 in intestinal epithelial cell injury during endotoxemia
}

\author{
Zhihao Liu', Jie Jiang ${ }^{2}$, Weigang Dai ${ }^{3}$, Hongyan Wei ${ }^{1}$, Xiaofei Zhang ${ }^{4}$, Zhen Yang ${ }^{1}$ and Yan Xiong ${ }^{1}$
}

\begin{abstract}
Intestinal mucosal integrity dysfunction during endotoxemia can contribute to translocation of intestinal bacteria and a persistent systemic inflammatory response, which both fuel the pathophysiological development of sepsis or endotoxemia. The pathogenesis of intestinal damage induced by endotoxemia remains poorly understood. Here, we identified the microRNA (miR)-674-5p/X-box binding protein 1 (XBP-1) axis as a critical regulator and therapeutic target in preventing intestinal crypt cell proliferation during endotoxemia. MiR-674-5p was markedly increased in intestinal epithelial cells (IECS) during endotoxemia and its induction depended on hypoxia-inducible factor-1a (HIF-1a). Intriguingly, gene expression microanalysis revealed that expression of XBP-1 was down-regulated in IECs with overexpression of miR-674-5p. miR-674-5p was found to directly target XBP-1 protein expression. Upon in vitro, anti-miR674-5p enhanced sXBP-1 expression and facilitated intestinal crypt cell proliferation. Blockade of miR-674-5p promoted XBP-1 activity, attenuated intestinal inflammation, and expedited intestinal regeneration, resulting in protection against endotoxemia-induced intestinal injury in mice. More importantly, the survival in endotoxemia mice was significantly improved by inhibiting intestinal miR-674-5p. Collectively, these data indicate that control of a novel miR674-5p/XBP-1 signaling axis may mitigate endotoxemia -induced intestinal injury.
\end{abstract}

\section{Introduction}

Endotoxemia is the most common cause of mortality in most intensive care units and accounts for more than 250,000 deaths in the United States annually ${ }^{1}$. Endotoxemia is the host inflammatory response to severe, lifethreatening infection, and results in organ dysfunction, including lung, kidney, and intestine ${ }^{2}$. Endotoxemiainduced intestinal injury is believed to have an important impact on the pathophysiology of endotoxemia and is considered the "motor" of the systemic inflammatory

\footnotetext{
Correspondence: Zhen Yang (yangzhen10710710@163.com) or

Yan Xiong (xiongyan@mail.sysu.edu.cn)

'Division of Emergency Medicine, Department of General Internal Medicine, Department of Emergency Intensive Care Unit, The First Affiliated Hospital of Sun Yat-sen University, No.58, Zhongshan 2nd Road, 510080 Guangzhou, China

2Department of Gastroenterology, The Third Affiliated Hospital of Sun Yat-Sen University, No.600, Tianhe Road, 510360 Guangzhou, China

Full list of author information is available at the end of the article These authors contributed equally: Zhihao Liu, Jie Jiang, Weigang Dai Edited by A. Rufini
}

response $^{3,4}$. Endotoxemia induces several aberrations in the intestinal epithelium involving barrier dysfunction ${ }^{3,4}$, magnified epithelial apoptosis ${ }^{5-7}$, and production of several inflammatory factors ${ }^{8,9}$. Moreover, intestinal epithelial integrity plays a vital role in physical barrier dysfunction induced by endotoxemia. The small intestinal epithelium normally renews every three and a half days with proliferated and differentiated cells moving from the crypts to the tip of villi ${ }^{10}$. Intestinal integrity, which is achieved by a balance of cell proliferation and cell death, has been shown to be injured in inflammatory pathological conditions such as endotoxemia or inflammatory bowel disease $\mathrm{e}^{11,12}$. Recent evidence has suggested that impaired cell proliferation is a critical factor in disturbing intestinal epithelial integrity in endotoxemia ${ }^{13}$. Given that intestinal cell proliferation is important in endotoxemiainduced intestinal injury, researchers have been seeking protective agents for the intestine that would encourage

\section{(c) The Author(s) 2020}

(c) (i) Open Access This article is licensed under a Creative Commons Attribution 4.0 International License, which permits use, sharing, adaptation, distribution and reproduction cc) in any medium or format, as long as you give appropriate credit to the original author(s) and the source, provide a link to the Creative Commons license, and indicate if changes were made. The images or other third party material in this article are included in the article's Creative Commons license, unless indicated otherwise in a credit line to the material. If material is not included in the article's Creative Commons license and your intended use is not permitted by statutory regulation or exceeds the permitted use, you will need to obtain permission directly from the copyright holder. To view a copy of this license, visit http://creativecommons.org/licenses/by/4.0/. 
intestinal cell proliferation and maintain intestinal cell homeostasis.

MicroRNAs (miRNAs) are a class of noncoding RNA molecules and endogenously expressed RNAs of 21-23 nucleotides that bind with partial sequence homology to the $3^{\prime}$-untranslated region (UTR) of target mRNAs and inhibit translation ${ }^{14}$. High-throughput and functional studies have shown that miRNAs play crucial roles in many aspects of cellular physiology as well as pathological processes such as inflammation and tumorigenesis ${ }^{14,15}$. Recently, miRNAs have been shown to function as modulators in the regulation of various aspects of gut epithelial homeostasis, including intestinal cell proliferation, apoptosis, and differentiation ${ }^{16-18}$. Several intestinal epithelial-specific miRNAs, including miR- $222^{17}$, miR$322 / 503^{19,20}$, miR-21/155 ${ }^{21}$, miR- $195^{22}$, miR- $122 \mathrm{~b}^{23}$, and miR-29b ${ }^{24}$, have been found to modulate intestinal epithelial cell (IEC) proliferation, apoptosis, and cell-to-cell interaction. However, the roles of miRNAs in endotoxemia-induced intestinal injury remain to be explored.

In the present study, we identified changes in the expression of 10 miRNAs from a total of 30 novel miRNAs chosen from the miRNA expression profile of mouse embryos $^{25}$ with endotoxemia-induced intestinal injury. Moreover, we identified miR-674-5p as a key miRNA that was markedly induced in endotoxemia-induced intestinal injury and was found to target X-box binding protein 1 (XBP-1), which in turn, inhibited intestinal crypt cell proliferation and exacerbated intestinal injury during endotoxemia.

\section{Results}

\section{Upregulation of miR-674-5p in mouse IECs during} endotoxemia-induced intestinal injury

Total RNA was extracted from IECs isolated from small intestines of mice treated with LPS and used to investigate altered expression of miRNAs by real-time PCR. Of $\sim 30$ miRNAs selected from the expression profile of miRNAs in mouse embryos ${ }^{25}$, only 10 miRNAs in IECs of mice exhibited a significant change in expression following LPS treatment. While miRNAs 681, 719, 33, and 695 were downregulated, miRNAs 711, 16-1, 345, 674-5p, 301, and 143 were upregulated (Fig. 1a, b). Among these miRNAs, miR-674-5p exhibited the highest upregulation following LPS treatment. A similar change in miR-674-5p expression was also observed in IECs of endotoxemia mice treated with S. aureus (Fig. 1c). miR-674-5p induction in IECs during endotoxemia-induced intestinal injury was confirmed by northern blotting (Fig. 1d). miR-674-5p was previously identified via parallel signature sequencing technology, but its targets and function have remained elusive. Next, we investigated the function and significance of miR-674-5p in mouse IECs following LPS treatment.

\section{HIF-1a mediates induction of miR-674-5p during LPS stimulation}

HIF- $1 \alpha$ has been shown to be critical in regulating inflammatory gene expression in various tissues and organs, including the intestine ${ }^{26-28}$. Therefore, we explored the connection between HIF-1 $\alpha$ and miR-674-5p induction during LPS stimulation. In vitro, LPS stimulation markedly induced miR-674-5p and HIF- $1 \alpha$ in IEC-6 cells (Fig. 2a, b). Moreover, HIF-1 $\alpha$ was gradually increased at $48 \mathrm{~h}$ after LPS stimulation (Fig. 2c). Following HIF- $1 \alpha$ knockdown which was confirmed by HIF- $1 \alpha$ siRNA, miR-674-5p induction was significantly reduced (Fig. 2d). To further investigate whether miR-674-5p induction depends on HIF- $1 \alpha$, wild-type and HIF- $1 \alpha$-null MEFs were stimulated with LPS and miR-674-5p expression was analyzed. We found that miR-674-5p was promoted by LPS stimulation in wild-type MEFs but not in HIF-1 $\alpha$-null MEFs (Fig. 2e). Additionally, ChIP analysis demonstrated the binding of HIF- $1 \alpha$ to the promoter region of miR-674-5p in MEFs (Fig. 2f). These results suggest that HIF- $1 \alpha$ is important in inducing miR674 expression under LPS stimulation.

\section{Expression of XBP-1 is decreased in miR-674-5p-treated human IECs}

Gene expression microanalysis was performed to screen for changes in gene expression of several apoptosis-, autophagy-, and endoplasmic reticulum (ER) stressrelated genes in human intestinal epithelial cells (FHCs) treated with miR-674-5p or the scrambled. We found that expression of CASP10, CASP1, CASP7, BCL-2, IREB2, and ATG5 was significantly increased by less than onefold (Fig. 3a, b). On the contrary, only two genes, ATF-6 and XBP-1, showed a significant decrease in expression of more than three-fold in miR-674-5p-treated FHCs (Fig. 3a, b). This indicates that miR-674-5p may regulate XBP-1 expression.

\section{XBP-1 over-expression improves IEC proliferation under LPS stimulation}

Gene expression microanalysis demonstrated that expression of XBP-1 and ATF- 6 is important in LPStreated IECs. Since XBP-1 has previously been shown to facilitate cell survival and increase epithelial neoplasia in several pathological conditions ${ }^{29,30}$, we investigated the role of XBP-1 in endotoxemia-induced IEC injury. Following in vitro transfection of XBP-1 (Fig. 4a, b), cell proliferation was greatly enhanced in IEC-6 cells overexpressing XBP-1 when subjected to LPS stimulation (Fig. 4b, c). XBP-1 transfection upregulated the expression of XBP-1 and other proliferative proteins such as STAT3, Bmi1, and Notch1 (Fig. 4a, d). Increased cell proliferation was not observed in IEC-6 cells with ATF- 6 or eIF- $2 \alpha$ transfection following LPS treatment (Fig. 4e, f). 

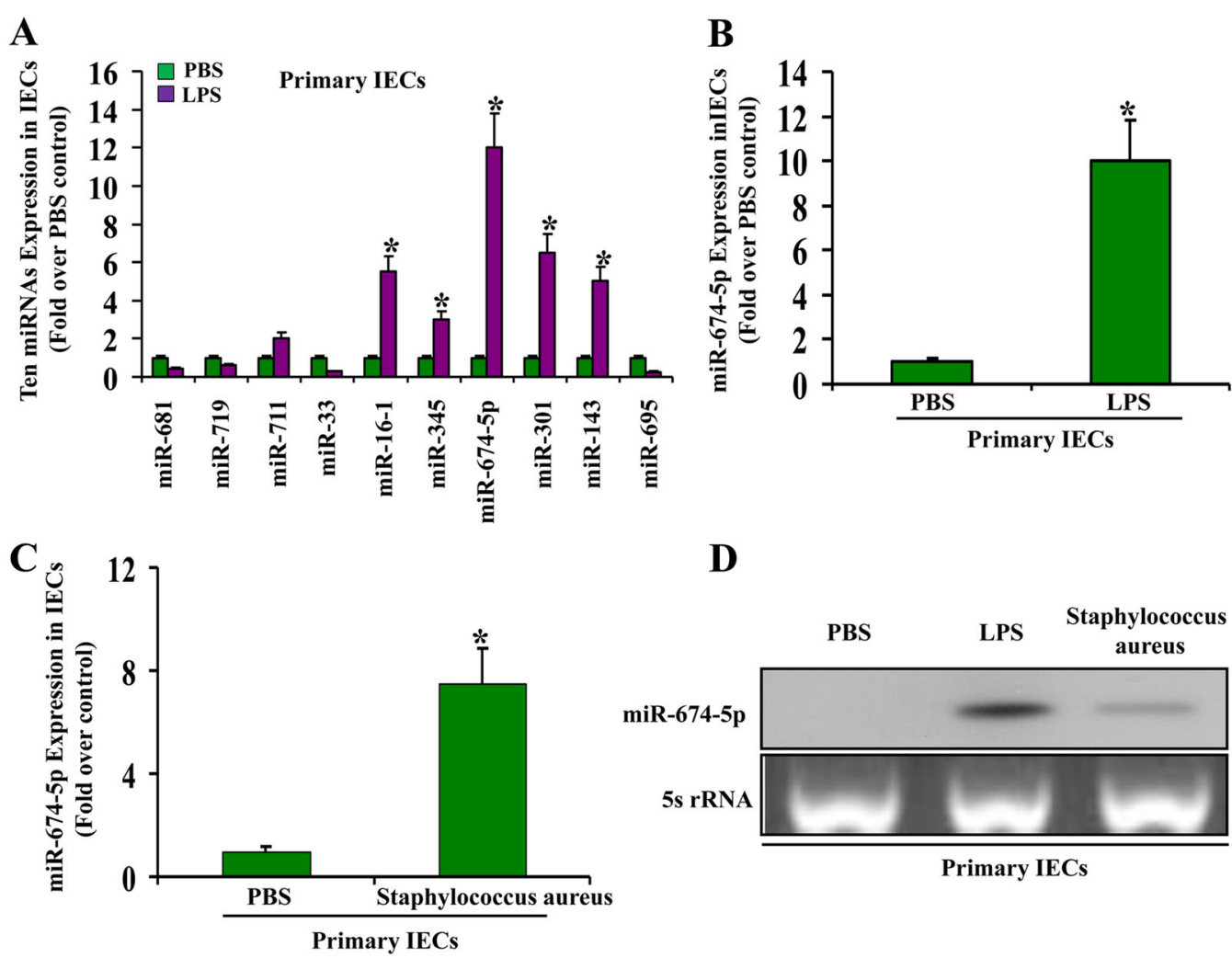

D

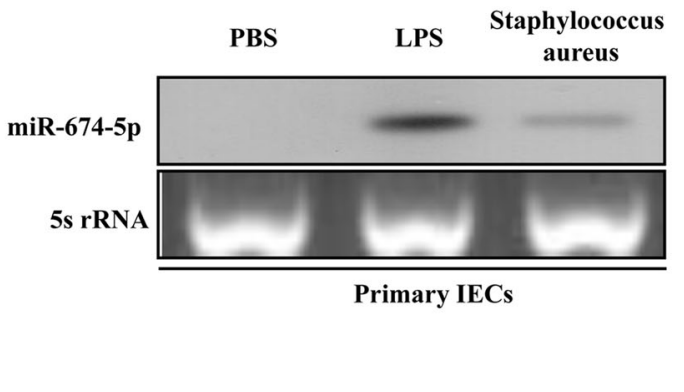

Fig. 1 Upregulation of miR-674-5p in mouse IECs during endotoxemia-induced intestinal injury. a Significant changes in miRNA expression in IECS of small intestines isolated from mice at day 3 after treated with lipopolysaccharide (LPS) or phosphate-buffered saline (PBS) during endotoxemia-induced intestinal injury. Values are presented as means \pm standard deviation (SD), $n=6$ in each group. ${ }^{*} P<0.05$ versus PBS. b Realtime PCR of miR-674-5p. RNA from IECs isolated from small intestines of mice at day 3 after injected with LPS or PBS. Values are presented as means \pm SD, $n=6$ in each group. ${ }^{*} P<0.01$ versus PBS. $\mathbf{c}$ Real-time PCR of miR-674-5p. RNA from IECs isolated from small intestines of mice at day 3 after treated with Staphylococcus aureus or PBS. Values are presented as means $\pm S D, n=6$ in each group. ${ }^{*} P<0.05$ versus PBS. $\mathbf{d}$ Northern blot analysis of miR-674-5p. Total RNA $(10 \mu \mathrm{g})$ extracted from IECs isolated from mice at day 3 after treated with LPS, S. aureus, or PBS were used for northern blotting. $5 S$ rRNA was probed as a loading control.

These data confirm that XBP-1 has a protective impact on LPS-induced IEC injury in vitro.

\section{miR-674-5p targets XBP-1 during LPS stimulation}

Next, we investigated whether XBP-1 is a downstream target of miR-674-5p. Using the Targetscan database, target prediction indicated that XBP-1 may be a potential target of miR-674-5p. miR-674-5p was found to bind to the $3^{\prime}$ UTR of XBP- 1 mRNA in various animal species (Fig. 5a). Transfection of a miR-674-5p mimic decreased XBP-1 expression in CCC-HIE-2 cells after $72 \mathrm{~h}$ (Fig. 5b). Furthermore, we explored the effect of miR-674-5p on the $3^{\prime}$ UTR of XBP-1 using the miRNA target luciferase reporter system. The $3^{\prime}$ UTR of XBP-1 and its reverse sequence (control $3^{\prime}$ UTR) were cloned downstream of the luciferase reporter gene activated by a constitutive promoter. The constructs were transfected into CCC-HIE-2 cells with miR-674-5p mimic or a sequence-scrambled oligonucleotide.
The miR-674-5p mimic significantly weakened luciferase expression in luciferase-XBP-1 $3^{\prime}$ UTR-transfected cells, while the sequence-scrambled oligonucleotide had no effect (Fig. 5c). As expected, luciferase expression was not significantly changed with the miR-674-5p mimic or the sequence-scrambled oligonucleotide in luciferase-control 3' UTR-transfected cells. Our results suggest that miR-674-5p directly blocks XBP-1 expression. In IEC- 6 cells, XBP-1 expression remained relatively stable following LPS stimulation, but a dramatic increase in SXBP-1 and XBP-1 expression was observed following treatment with the anti-miR-674-5p oligonucleotide (Fig. 5d). Similarly, in mouse colonic adenocarcinoma CT-26 cells, miR-674-5p expression increased following LPS stimulation and blocking miR674-5p markedly upregulated sXBP-1 and XBP-1 expression (Fig. 5e). These results indicate that miR674-5p directly targets XBP-1 expression under conditions of LPS stimulation. 

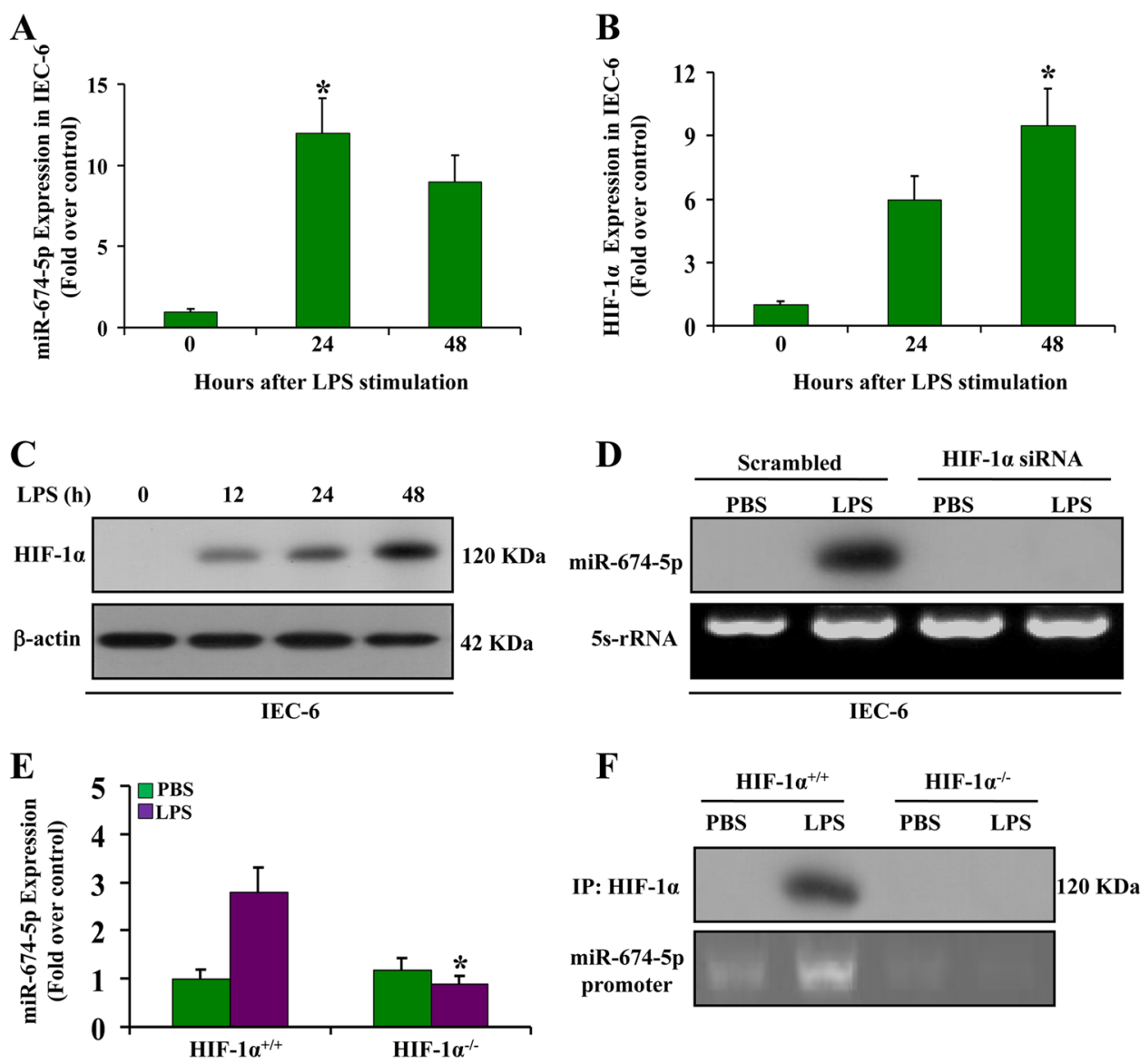

Fig. 2 HIF-1a mediates induction of miR-674-5p during LPS stimulation. a Induction of miR-674-5p by LPS stimulation. IEC-6 cells were stimulated for $12-48 \mathrm{~h}$ to extract RNA for real-time PCR analysis of miR-674-5p. Fold changes over the value of IECs treated with PBS (arbitrarily set as 1) are shown. Values are presented as means \pm SD, $n=6$ in each group. ${ }^{*} P<0.01$ versus IECs treated with PBS. $\mathbf{b}$ Induction of HIF-1a by LPS stimulation. IEC-6 cells were stimulated for 12-48 $\mathrm{h}$ to extract RNA for real-time PCR analysis of HIF-1a. Fold changes over the value of IEC cells treated with PBS (arbitrarily set as 1). Values are presented as means \pm SD, $n=6$ in each group. ${ }^{*} P<0.05$ versus IECs with PBS. $\mathbf{c}$ Western blot analysis of HIF1a in IEC-6 cells was carried out with whole cell lysates collected at various time points after LPS stimulation. $\mathbf{d}$ IEC- 6 cells transfected with a sequence-scrambled oligonucleotide control or HIF-1a small interfering RNA were subjected to LPS stimulation, and whole cell lysates were collected at $24 \mathrm{~h}$. e Induction of miR-674-5p by LPS stimulation. HIF-1 $\mathrm{a}^{+/+}$and HIF-1 $\mathrm{a}^{-/-}$mouse embryonic fibroblasts were stimulated for $24 \mathrm{~h}$ to extract RNA for real-time PCR analysis of miR-674-5p. Fold changes over the value of HIF-1 $a^{+/+}$cells with LPS (arbitrarily set as 1 ) are shown. ${ }^{*} P<0.01$ versus HIF$1 a^{+/+}$cells with LPS. f HIF-1a binding to the miR-674-5p promoter during LPS stimulation. HIF-1a ${ }^{+/+}$and $\mathrm{HIF}^{-1 a^{-/-}}$cells were stimulated with LPS or PBS for $24 \mathrm{~h}$. Cell lysates were collected for chromatin immunoprecipitation analysis of HIF-1a binding to miR-674-5p promoter DNA.

Suppression of miR-674-5p protects against endotoxemiainduced intestinal injury by regulating XBP-1

To study the role of miR-674-5p in endotoxemiainduced intestinal injury in vivo, we used systemic injection of anti-miR-674-5p oligonucleotide to specifically lower miR-674-5p expression in mouse IECs. With injection of anti-miR-674-5p oligonucleotide three times, miR-674-5p was significantly downregulated in IECs (Fig. $6 a, b)$. Mice that received anti-miR-674-5p oligonucleotide showed significantly less intestinal epithelium injury than those that received the sequence-scrambled oligonucleotide control (Fig. 6c, d). The inflammatory biomarkers Tumor necrosis factor (TNF)- $\alpha$ and interleukin (IL)-6 were also reduced in small intestinal mucosa of
anti-miR-674-5p-treated mice compared the control (Fig. $6 \mathrm{e}, \mathrm{f})$. Given that intestinal inflammation is closely associated with intestinal permeability and integrity, a bacterial burden assay was performed and intestinal proliferation was assessed. We found that the bacterial burden was markedly alleviated (Fig. 6g) and IEC proliferation was significantly improved in endotoxemia mice with anti-miR-674-5p oligonucleotide (Fig. 6h). Further analysis revealed that with LPS-induced ER stress, blocking miR-674-5p distinctly boosted XBP-1 expression, but not that of eIF- $2 \alpha$ and ATF-6 (Fig. 6i). XBP-1 has been shown to promote cell survival in pathophysiological conditions $^{29}$. The morphological and molecular changes in endotoxemia mice treated with anti-miR-674-5p 


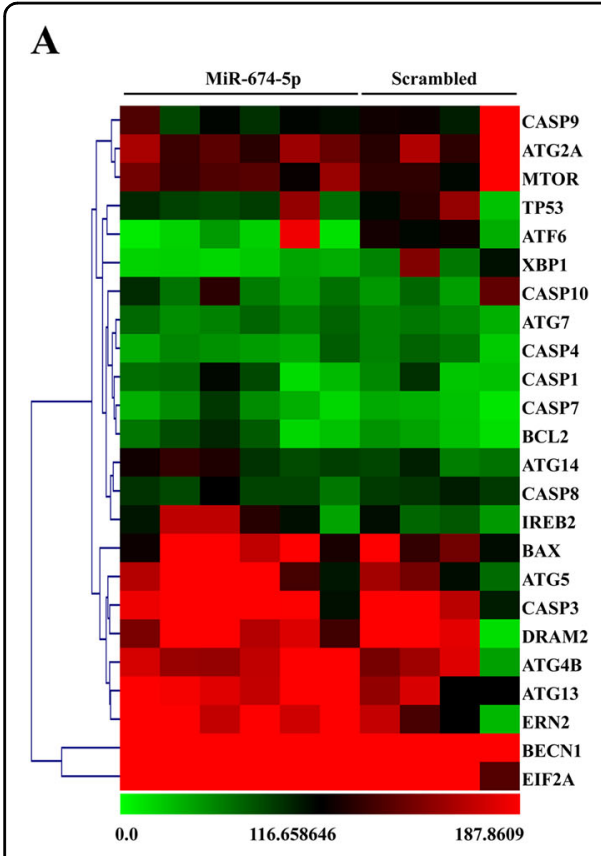

B

Gene expression in MiR-674-5p-treated human intestinal epithelial cells compared with the scrambled-treated

\begin{tabular}{|c|c|c|c|c|}
\hline Gene & Description & Regulation & Fold Change & $P$ \\
\hline CASP9 & "Homo sapiens caspase 9" & Down & 1.2357 & 0.6611 \\
\hline ATG2A & "Homo sapiens autophagy related $2 \mathrm{~A}$ " & Down & 1.1086 & 0.6800 \\
\hline MTOR & "Homo sapiens mechanistic target of rapamycin kinase" & Down & 1.0103 & 0.7000 \\
\hline TP53 & "Homo sapiens tumor protein p 53 " & Down & 1.0466 & 0.6900 \\
\hline ATF6 & "Homo sapiens activating transcription factor 6" & Down & 3.5911 & 0.0134 \\
\hline XBP1 & "Homo sapiens X-box binding protein 1" & Down & 3.1975 & 0.0195 \\
\hline CASP10 & "Homo sapiens caspase $10 "$ & Up & 0.7508 & 0.0373 \\
\hline ATG7 & "Homo sapiens autophagy related 7" & Up & 0.8943 & 0.5414 \\
\hline CASP4 & "Homo sapiens caspase 4" & Down & 1.0915 & 0.6867 \\
\hline CASP1 & "Homo sapiens caspase 1" & Up & 0.4304 & 0.0148 \\
\hline CASP7 & "Homo sapiens caspase 7" & Up & 0.4643 & 0.0174 \\
\hline BCL2 & "Homo sapiens BCL2, apoptosis regulator" & Up & 0.347 & 0.0245 \\
\hline ATG14 & "Homo sapiens autophagy related 14 " & Up & 0.6706 & 0.0801 \\
\hline CASP8 & "Homo sapiens caspase 8" & Up & 0.9187 & 0.5690 \\
\hline IREB2 & "Homo sapiens iron responsive element binding protein 2" & Up & 0.5018 & 0.0164 \\
\hline BAX & "Homo sapiens BCL2 associated X, apoptosis regulator" & Down & 1.0355 & 0.6870 \\
\hline ATG5 & "Homo sapiens autophagy related 5 " & Up & 0.6012 & 0.0433 \\
\hline CASP3 & "Homo sapiens caspase 3" & Up & 0.7455 & 0.2823 \\
\hline DRAM2 & "Homo sapiens DNA damage regulated autophagy modulator 2" & Up & 0.6289 & 0.3226 \\
\hline ATG4B & "Homo sapiens autophagy related $4 \mathrm{~B}$ cysteine peptidase" & Up & 0.8605 & 0.5414 \\
\hline ATG13 & "Homo sapiens autophagy related 13 " & Up & 0.8291 & 0.4162 \\
\hline ERN2 & "Homo sapiens endoplasmic reticulum to nucleus signaling 2" & Up & 0.5833 & 0.1255 \\
\hline BECN1 & "Homo sapiens beclin 1" & Up & 0.6293 & 0.5161 \\
\hline EIF2A & "Homo sapiens eukaryotic translation initiation factor $2 \mathrm{~A}$ " & Down & 1.1031 & 0.6910 \\
\hline
\end{tabular}

Fig. 3 Expression of XBP-1 is decreased in miR-674-5p-treated human IECs. a Two-dimensional hierarchical clustering for apoptosis-, autophagy-, and endoplasmic reticulum (ER) stress-related genes among human IECs-FHC cells in $24 \mathrm{~h}$ after transfected with miR-674-5p or scrambled treatment. Fold changes in mRNA levels in FHC cells treated with miR-674-5p or scrambled are represented by green and red squares, showing decreased and increased levels, respectively. $\mathbf{b}$ Apoptosis-, autophagy-, and ER stress-related genes among human IECs-FHC cells in 24 hours after transfected with with miR-674-5p or scrambled treatment. The ratio represents the expression value in FHC cells with miR-674-5p-treated FHC cells compared with scramble-treated FHC cells.

oligonucleotide suggest that inhibition of miR-674-5p prolongs survival of endotoxemia mice (Fig. 6j). These results suggest that miR-674-5p-mediated downregulation of XBP-1 is important for the development of endotoxemia-induced intestinal injury.

\section{Blockade of miR-674-5p encourages intestinal crypt cell proliferation via XBP-1 under LPS stimulation}

The above in vivo experiment implied that blocking miR-674-5p has a protective effect in endotoxemiainduced intestinal injury via regulation of XBP-1. We further studied the effect of miR-674-5p in vitro under LPS stimulation. Intestinal crypt cells, regarded as intestinal progenitor/stem cells, were isolated from small intestine of mice. Ki67, known as an frequently-used measurement for propagation, was solely expressed in intestinal crypts, not in villi and in isolated crypt cells (Supplementary Fig. 1A-C). Isolated crypt cells could form large colonies within 21 days (Supplementary Fig. 1D). However, proliferative capacity of intestinal crypt cells was reduced by $75 \%$ following LPS treatment, and was subsequently increased by $\sim 50 \%$ following treatment with anti-miR-674-5p oligonucleotide (Fig. 7a, b). The two biomarkers for proliferation Notch1 and Bmil were greatly down-regulated in isolated intestinal crypt cells after LPS treatment, which could be significantly promoted by anti-miR-674-5p (Fig. 7c, d). More importantly, the ER stress-related proteins SXBP-1, but not ATF- 6 and eIF- $2 \alpha$, were significantly increased in intestinal crypt cells treated with anti-miR-674-5p oligonucleotide compared with the sequence-scrambled oligonucleotide control (Fig. $7 \mathrm{e}$. These results further support that miR-674-5p inhibits proliferation of intestinal crypt cells in response to LPS treatment through XBP-1 pathway.

\section{Discussion}

This study identified an miRNA-mediated signaling pathway that regulates endotoxemia-induced intestinal injury. We demonstrated that miR-674-5p is a critical mediator in preventing IEC proliferation in the intestine in response to endotoxemia. Tissue microarray analysis and the luciferase assay demonstrated that XBP-1 was a direct target of miR-674-5p and that the miR-674-5p-mediated decrease in XBP-1 increased intestinal inflammation and inhibited intestinal crypt cell proliferation. Inhibiting miR-674-5p markedly mitigated intestinal injury induced by endotoxemia and increased survival. To our knowledge, there are only a few studies in which a single miRNA has been reported to significantly exacerbate intestinal epithelial damage following endotoxemia or sepsis by inhibiting IEC proliferation. 

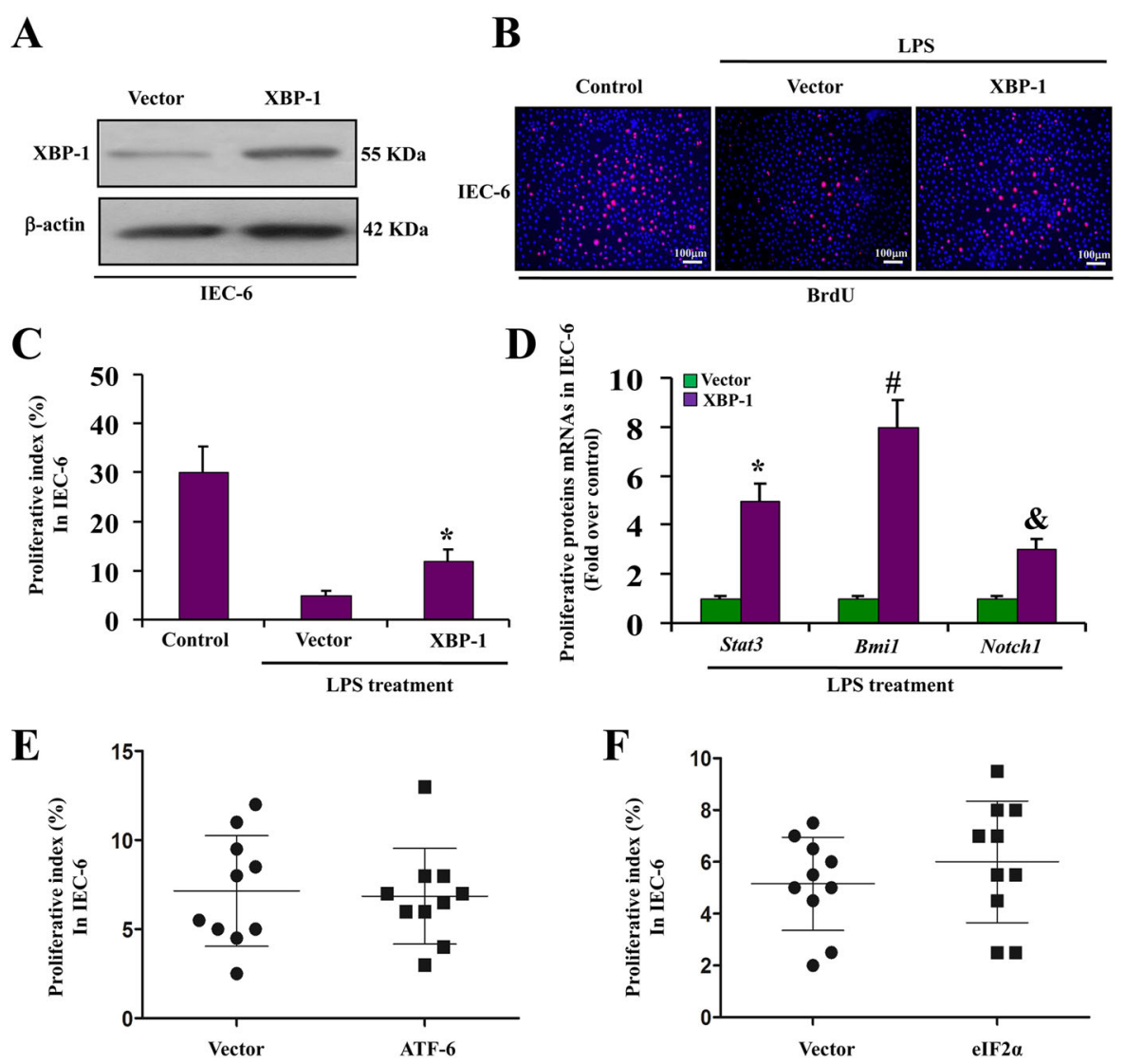

Fig. 4 XBP-1 overexpression improves IEC proliferation under LPS stimulation. a Western blot analysis of XBP-1 in IEC- 6 cells at $24 \mathrm{~h}$ with or without transfection of XBP-1. $\beta$-actin was used as a loading control. $\mathbf{b}$ BrdU staining of IEC-6 cells at $24 \mathrm{~h}$ after LPS stimulation with or without transfection of XBP-1. c Proliferative index was measured at $24 \mathrm{~h}$ after LPS stimulation by counting a minimum of 20 randomly selected microscopy fields ( $\times 200$ magnification) following BrdU staining. The index was obtained by dividing the number of BrdU-positive cells by the total number of cells. ${ }^{*} P<0.01$ versus vector control. d Real-time PCR analysis of STAT3, Bmi1, and Notch1. RNA from IEC-6 cells treated with LPS. ${ }^{*} P<0.05$ versus vector control, ${ }^{\#} P<0.01$ versus vector control, and ${ }^{\circledR} P<0.05$ versus vector control. e Proliferative index was measured at $24 \mathrm{~h}$ after LPS stimulation with transfection of ATF- 6 by counting a minimum of 20 randomly selected microscopy fields $(\times 200)$ following BrdU staining. The index was obtained by dividing the number of BrdU-positive cells by the total number of cells. ${ }^{*} P<0.05$ versus vector control. $\mathbf{f}$ Proliferative index was measured at $24 \mathrm{~h}$ after LPS stimulation with transfection of elF-2a by counting a minimum of 20 randomly selected microscopy fields ( $\times 200)$ following BrdU staining. The index was obtained by dividing the number of BrdU-positive cells by the total number of cells. ${ }^{*} P<0.01$ versus vector control.

To study the role of miR-674-5p in endotoxemiainduced intestinal injury in vivo, systemic injection of anti-miR-674-5p oligonucleotides to block miR-674-5p in IECs was performed. miR-674-5p was found to markedly inhibit IEC proliferation under conditions of endotoxemia, suggesting that directly blocking miR674-5p expression in IECs may be a potential therapeutic target to alleviate intestinal injury following endotoxemia. Moreover, miR-674-5p induction in IECs could be directly controlled by modulating HIF- $1 \alpha$ expression. Several studies have indicated that HIF- $1 \alpha$ expression is significantly induced under inflammatory conditions ${ }^{26-28,31-33}$, which is consistent with our results (Fig. 2). HIF-1 $\alpha$-mediated changes in miRNA expression were found to have a critical effect on the initiation and development of several pathophysiological processes, including ischemic kidney injury, colitis, and gastric cancer ${ }^{26,34-37}$. The HIF-1 $\alpha /$ miRNA pathway induced by inflammation may be a universal feature of inflammation-associated diseases. In this study, induction of HIF- $1 \alpha$ following LPS stimulation in IECs facilitated the increase in miR-674-5p expression, resulting in cell proliferation impairment. This was supported by the evidence that the expression of miR-674-5p was abrogated in the absence of HIF- $1 \alpha$ in LPS-treated cells (Fig. 2 ), suggesting that control of the HIF- $1 \alpha /$ miR- $674-5 p$ pathway exerts cyto-protective effects in endotoxemiainduced intestinal injury. However, whether miR-674-5p modulates HIF- $1 \alpha$ in intestinal injury caused by endotoxemia remains to be answered. 
A

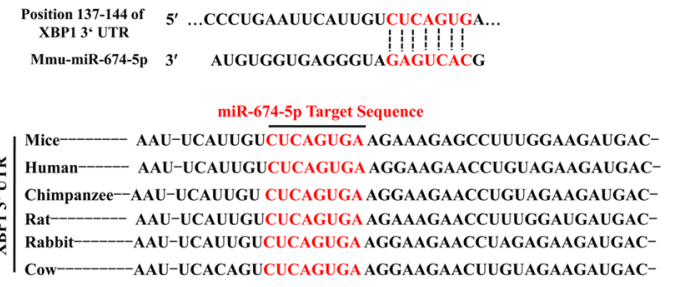

C

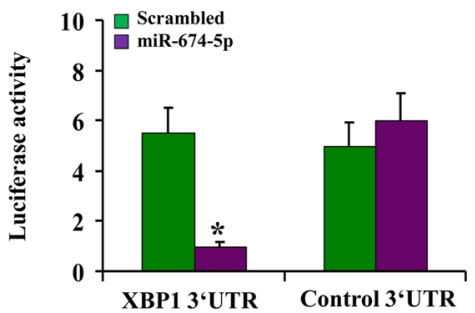

$\mathbf{E}$

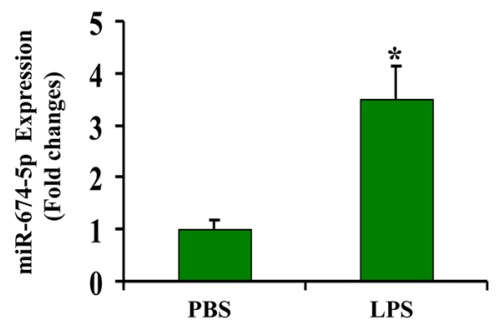

B

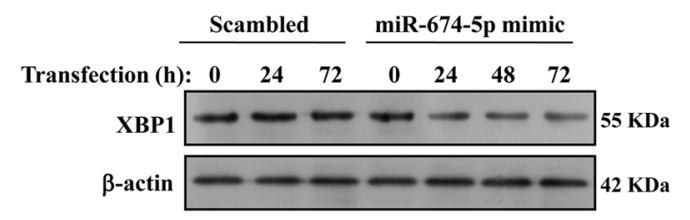

D

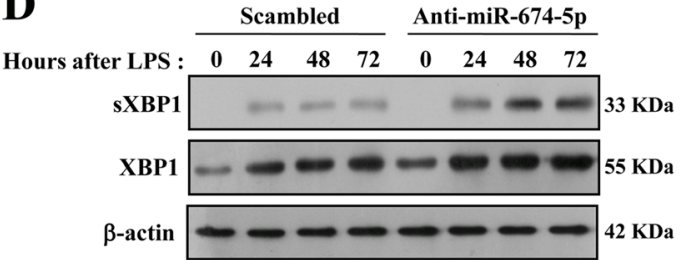

$\mathbf{F}$

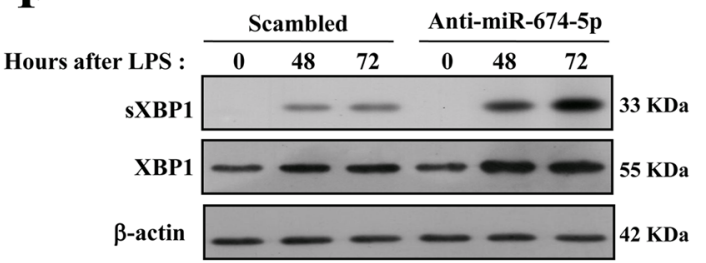

Fig. 5 miR-674-5p targets XBP-1 during LPS stimulation. a Upper: putative miR-674-5p complementary sequence in the $3^{\prime}$ untranslated region ( $3^{\prime}$ UTR) of murine XBP-1 mRNA. Lower: conserved miR-674 target sequence in the XBP-1 $3^{\prime}$ UTR. b CCC-HIE-2 cells were transfected with a sequencescrambled oligonucleotide control or miR-674-5p and western blotting was carried out from whole cell lysates collected at various time points. c Luciferase reporter assay was conducted using constructs with the XBP-1 $3^{\prime}$ UTR or an antisense control sequence. CCC-HIE-2 cells were cotransfected with these constructs along with the scrambled miRNA or miR-674 mimic. ${ }^{*} P<0.05$ versus control $3^{\prime}$ UTR. Three independent experiments were performed. d IEC-6 cells transfected with a scrambled control or anti-miR-674 oligonucleotide were stimulated with LPS, and whole cell lysates were collected at the indicated time points. Three independent experiments were performed. e Quantitative PCR analysis of miR674-5p gene expression at $24 \mathrm{~h}$ in CT-26 cells treated with LPS. ${ }^{*} P<0.05$ versus PBS. $\mathbf{f} C \mathrm{CT}-26$ cells transfected with a scrambled control or anti-miR-674 oligonucleotide were stimulated with LPS, and whole cell lysates were collected at the indicated time points. Western blotting of these lysates is shown.

$\mathrm{XBP}-1$ is a member of the CREB/ATF basic regionleucine zipper family of transcription factors and functions as a key factor in the unfolded protein or ER stress response $^{38}$. As one of three mechanistically distinct arms of the ER stress response, which include the Ire $1 \alpha / \mathrm{XBP}-1$, PERK/eIF2 $\alpha$, and ATF-6 pathways, cleavage of cytoplasmic XBP-1 by the endoribonuclease Ire $1 \alpha$ under conditions of ER stress results in nuclear translocation and upregulation of its target genes, the protein products of which operate in ER-associated degradation, the entry of proteins into the ER, and protein folding, which ultimately regulate inflammation, the immune system, and cell proliferation ${ }^{39-49}$. Previous studies have demonstrated that XBP-1 can modulate cell proliferation and tissue regeneration. In angiogenesis, $\mathrm{XBP}-1$ was found to boost vascular endothelial cell proliferation via growth factor signaling pathways. XBP-1 was also shown to be crucial for smooth muscle cell proliferation through transforming growth factor (TGF)- $\beta$-mediated pathways that accelerate neointimal formation ${ }^{42,43}$. Moreover, in epithelial cell homeostasis, XBP-1 appears to be required for proliferation of pancreatic acinar cells, $\beta$-cells, and hepatocytes, which in turn, expedite pancreatic and liver regeneration $^{44,46}$. In epithelial malignant neoplasms such as esophageal squamous cell carcinoma and breast cancer, XBP-1 could promote malignant cell propagation via different signaling pathways ${ }^{47,48}$. In this study, we demonstrated that blocking XBP-1 decreased the proliferation of IECs during endotoxemia and that by restraining miR-674-5p expression, enhanced XBP-1 could accelerate IEC proliferation, especially in the crypts, in endotoxemia-induced intestinal injury. However, one study showed that XBP-1 deficiency in IECs resulted in epithelial hyperproliferation via activation of 

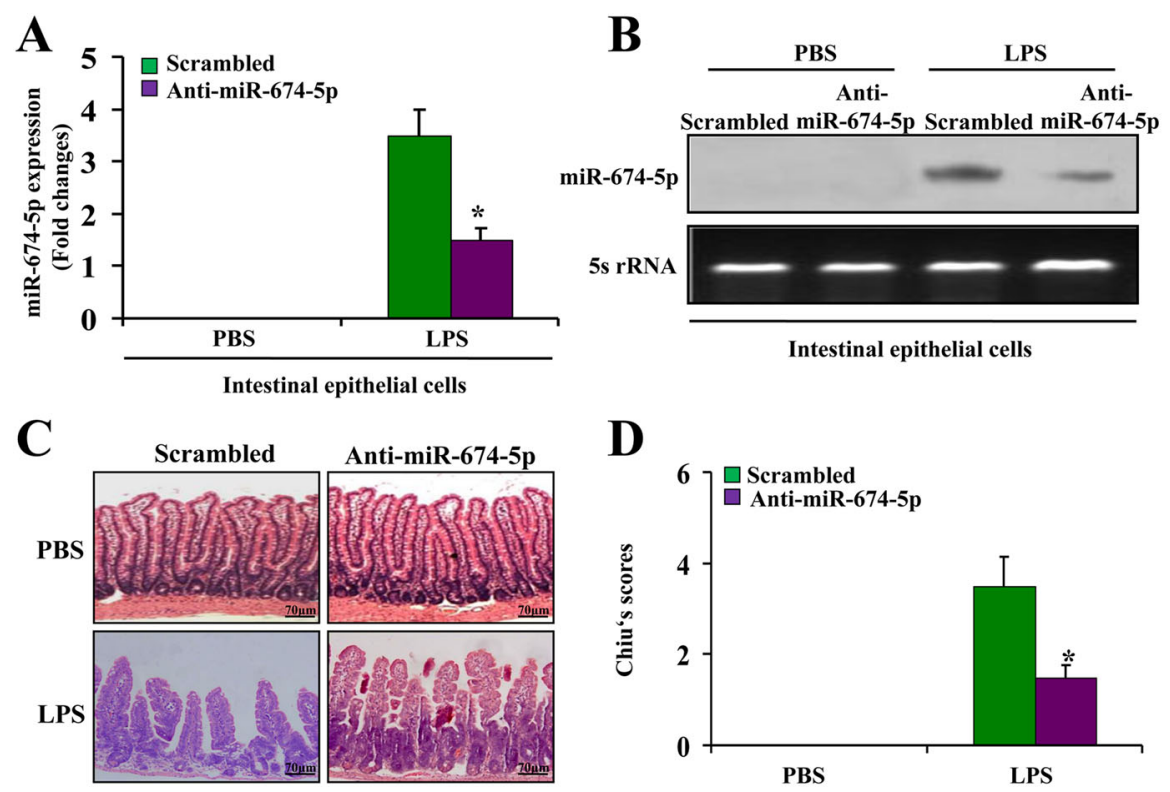

D

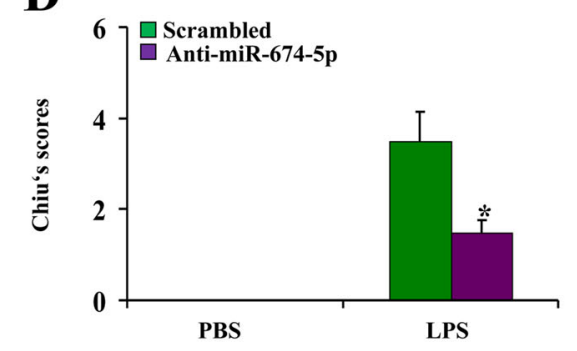

E

F
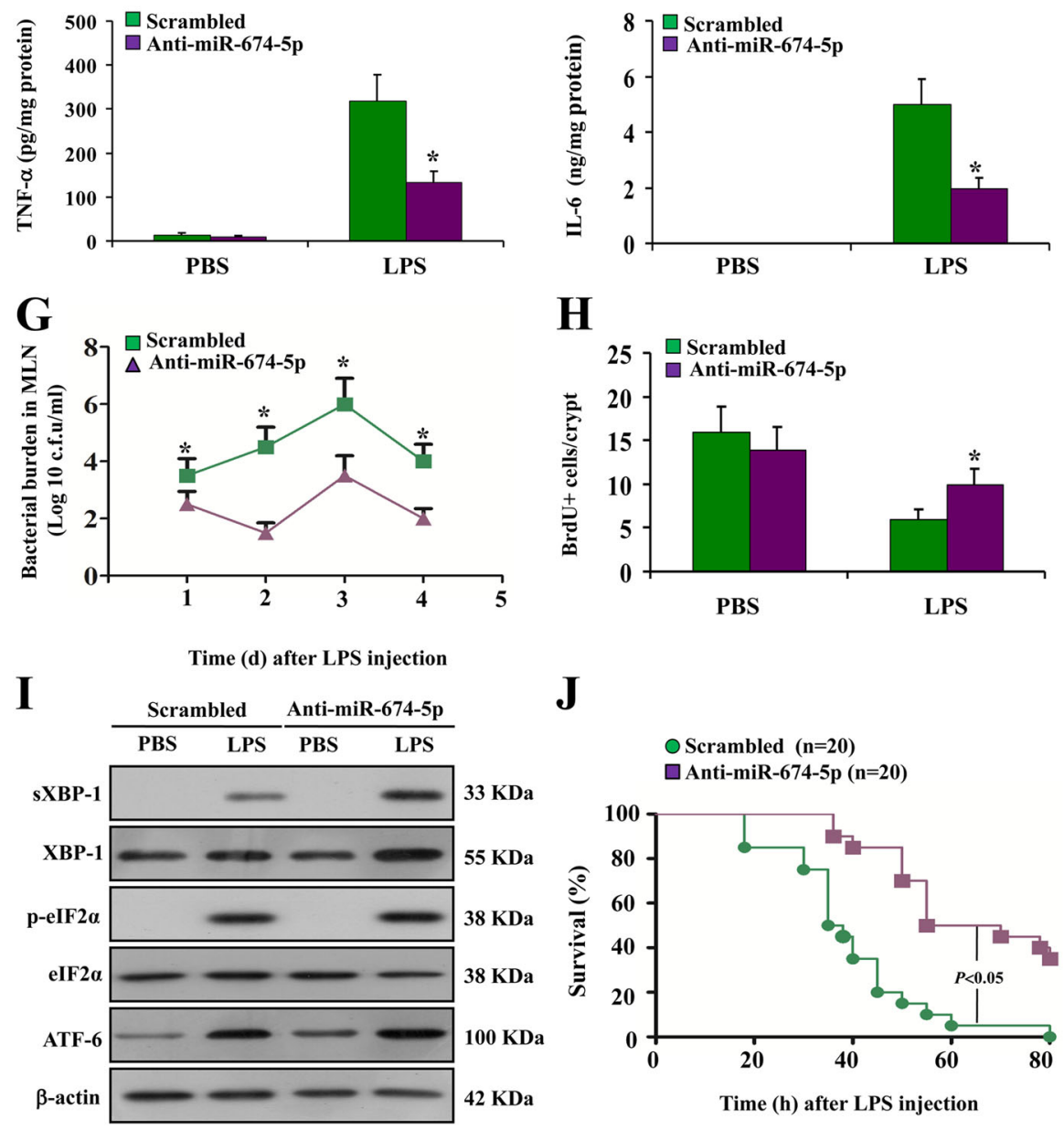

J

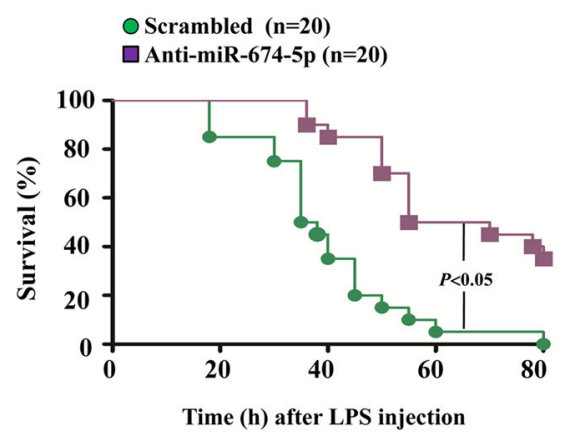

Fig. 6 (See legend on next page.) 
(see figure on previous page)

Fig. 6 Suppression of miR-674-5p protects against endotoxemia-induced intestinal injury by regulating XBP-1. a Real-time PCR of miR-674$5 \mathrm{p}$. RNA from IECs at $72 \mathrm{~h}$ after LPS treatment in mice with or without treatment with anti-miR-674-5p oligonucleotide. Values are presented as means $\pm S D, n=6$ in each group. ${ }^{*} P<0.01$ versus PBS. b Northern blot analysis of miR-674-5p. Total RNA (10 $\left.\mu g\right)$ extracted from IECs isolated from mice at $72 \mathrm{~h}$ after LPS treatment was used for northern blotting. $5 \mathrm{~S}$ rRNA was probed as a loading control. c Hematoxylin and eosin staining was performed using formalin-fixed tissue sections at day 5 after LPS treatment in mice with or without treatment with anti-miR-674 oligonucleotide or the sequence-scrambled oligonucleotide control. Magnification, $\times 400$. $\mathbf{d}$ Chiu's scores were measured and compared by analysis of variance with Tukey's post-hoc test. $* P<0.01$ versus scrambled control. Values are presented as means $\pm S D, n=6$ in each group. e Levels of TNF-a were measured at $72 \mathrm{~h}$ after LPS treatment in small intestinal mucosa of endotoxemia mice with or without treatment with anti-miR-674 oligonucleotide or the scrambled control. $* P<0.05$ versus scrambled. Values are presented as means $\pm S D, n=6$ in each group. $\mathbf{f}$ ELISA analysis of IL- 6 protein expression at $72 \mathrm{~h}$ after LPS treatment in small intestinal mucosa of endotoxemia mice with or without treatment with anti-miR-674 oligonucleotide or the scrambled control. $* P<0.01$ versus scrambled. Values are presented as means $\pm S D, n=6$ in each group. $\mathbf{g}$ Bacterial counts in mesenteric lymph nodes at continuous time points after LPS treatment in endotoxemia mice with or without treatment with anti-miR-674 oligonucleotide or the scrambled control. ${ }^{*} P<0.05$ versus scrambled. Values are presented as means $\pm S D, n=6$ in each group. $\mathbf{h}$ Average number of BrdU-positive cells in each crypt at $72 \mathrm{~h}$ following LPS treatment was determined by counting BrdU-positive cells in intact crypts. Values are presented as means \pm SD, $n=$ 6 in each group. ${ }^{*} P<0.05$ versus scrambled control. $\mathbf{i}$ Western blot analysis of ER stress-related proteins of IECs isolated from endotoxemia mice with or without treatment with anti-miR-674 oligonucleotide or the scrambled control. $\beta$-actin was used as a loading control. $\mathbf{j}$ Survival curves of endotoxemia mice with or without treatment with anti-miR-674 or the scrambled control.

A

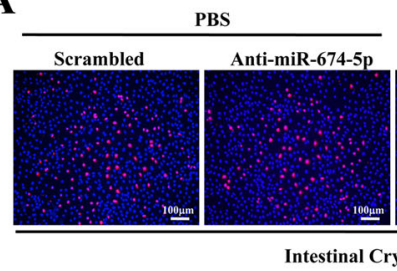

C

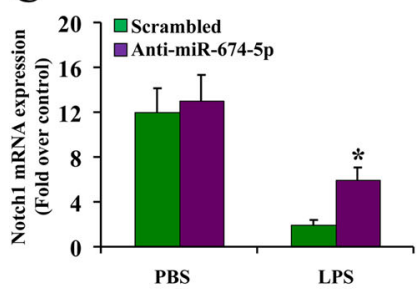

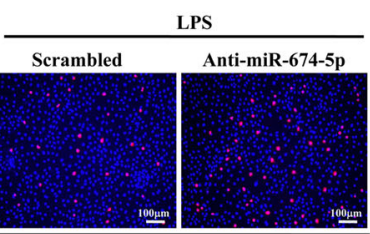

D

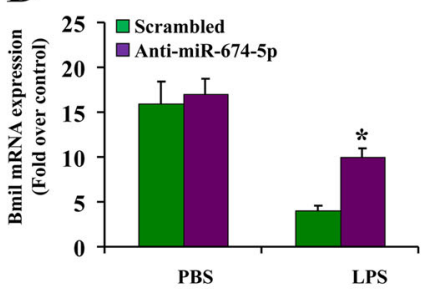

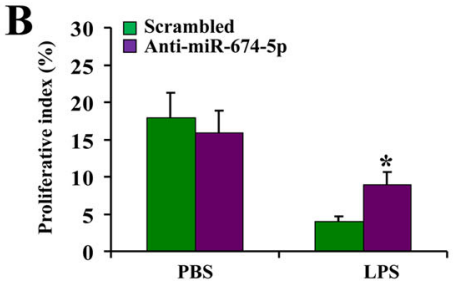

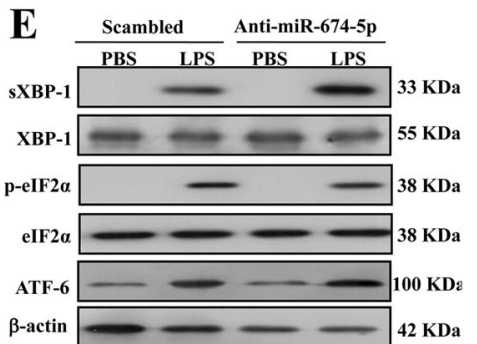

Fig. 7 Blockade of miR-674-5p encourages intestinal crypt cell proliferation via XBP-1 under LPS stimulation. a BrdU staining of intestinal crypt cells isolated from mice at $24 \mathrm{~h}$ after LPS stimulation with or without treatment with anti-miR-674 oligonucleotide or the sequence-scrambled oligonucleotide control. b Proliferative index was measured at $24 \mathrm{~h}$ after LPS treatment by counting a minimum of 20 randomly selected microscopy fields ( $\times 200$ magnification) following BrdU staining. The index was obtained by dividing the number of BrdU-positive cells by the total number of cells. ${ }^{*} P<0.01$ versus scrambled control. c RT-PCR analysis of Notch1 mRNA in intestinal crypt cells isolated from mice at $24 \mathrm{~h}$ after LPS treatment with or without treatment with anti-miR-674 oligonucleotide or the scrambled control. $* P<0.05$ versus scrambled control. $\mathbf{d}$ RT-PCR analysis of Bmi1 mRNA in intestinal crypt cells isolated from mice at $24 \mathrm{~h}$ after LPS treatment with or without treatment with anti-miR-674 or the scrambled. ${ }^{*} P<0.01$ versus scrambled control. e Western blot analysis of ER stress-related proteins of intestinal crypt cells at $24 \mathrm{~h}$ after LPS stimulation with or without treatment with anti-miR-674 oligonucleotide or the scrambled control. $\beta$-actin was used as a loading control.

STAT3 signaling ${ }^{49}$. The disparity between our findings and this study might be partly interpreted by the fact that PERK and XBP-1 act as two important branches of the ER stress response that can both promote IEC proliferation. IECs with knockout of XBP-1 exhibited unresolved ER stress due to hyperactivation of Ire1 $\alpha$; pathological ER stress could result in high expression of PERK, which could encourage IEC proliferation following injury ${ }^{49}$. In this study, blocking XBP-1, but not the PERK pathway, could mitigate IEC proliferation. Moreover, we identified the targeting of
XBP-1 by miR-674-5p as a potential therapeutic target for improving endotoxemia-induced intestinal injury.

In conclusion, this study has highlighted miR-674-5p as a critical miRNA in alleviating endotoxemia-induced intestinal injury. Elaboration of the HIF- $1 \alpha /$ miR-674-5p/ XBP-1 signaling pathway not only provides novel and important insight into the pathogenesis of intestinal injury by endotoxemia or endotoxemia, but also suggests a novel miRNA-based therapeutic target for prevention and treatment. 


\section{Materials and methods}

Animals, experimental sepsis and endotoxemia induction, and anti-miRNAs

The current study was approved by the Animal Care and Use Committee of Sun Yat-sen University, Guangzhou, China (approval number: 2018007). Experimental endotoxemia and sepsis model was induced respectively by administering lipopolysaccharide (LPS) from Escherichia coli $(17.5 \mathrm{mg} / \mathrm{kg}$, O55:B5; Sigma-Aldrich, St. Louis, MO, USA) intraperitoneally at a dose of $350 \mu \mathrm{g}$ in $100 \mu \mathrm{L}$ of saline or Staphylococcus aureus $\left(10^{8}\right.$ colony forming units [CFU] per mouse; ATCC 14458, SEB ${ }^{+}$TSST- $1^{-}$) intravenously to 4-6-week-old mice weighing $\sim 20 \mathrm{~g}$. C57BL/6 male mice were monitored at 4-h intervals through critical stages of disease and euthanized with chloral hydrate at objective, predefined endpoints: loss of circulation to tail or feet, loss of responsiveness to stimuli, or breathing rate $<120$ breaths per minute. Survivors were monitored intensively for 6 days and euthanized 15 days after injection of LPS. Small intestines were harvested 3 days after injection of LPS for immunological, histopathological, serological, and bacteriological analyses.

Anti-miRNA administration was performed as described elsewhere ${ }^{50}$. Separate solutions of anti-miR-674-5p oligonucleotide and its scrambled negative control (Ambion, Austin, TX, USA) were diluted with in vivojetPEI solution (Polyplus-transfection) containing 10\% (wt/vol) glucose at a ratio of in vivo-jetPEI nitrogen residues per oligonucleotide phosphate of 5 , according to the manufacturer's instructions. All solutions were shaken for $10 \mathrm{~s}$ and incubated for at least $15 \mathrm{~min}$ at $37^{\circ} \mathrm{C}$ prior to injection. Each mouse received $400 \mu \mathrm{L}$ of saline and oligonucleotide mixture (corresponding to $300 \mu \mathrm{g}$ of oligonucleotide per dose) through tail vein injection consecutively for at least 3 days before experimental endotoxemia, and continuously received it until tissue collection or for at most 6 days after LPS injection. The intestines were harvested $24 \mathrm{~h}$ after the last injection. All injections were performed using a 30-gauge needle syringe with a single mouse restrainer.

\section{Histology and intestinal BrdU staining}

A segment of the small intestine was stained with hematoxylin and eosin. Damage of the intestinal mucosa was evaluated using the criteria of Chiu's method ${ }^{51}$ by two independent experienced pathologists who were blinded to the study groups. A minimum of six randomly chosen fields of view from each mouse were evaluated under a microscope and averaged to determine mucosal damage, and the results of the two pathologists were averaged.

Mice were injected with BrdU $(150 \mathrm{mg} / \mathrm{kg}$; SigmaAldrich) $4 \mathrm{~h}$ prior to sacrifice. For BrdU staining, sections were deparaffinized and treated with proteinase $\mathrm{K}(20 \mu \mathrm{g} /$ $\mathrm{mL}$ ) for $20 \mathrm{~min}$ at $37^{\circ} \mathrm{C}$. The staining was performed following a standard protocol with anti-BrdU antibody (1:100 in $5 \%$ bovine serum albumin [BSA], SigmaAldrich) and secondary antibody (Santa Cruz Biotechnology, Inc., Santa Cruz, CA, USA), and color was developed using a DAB kit (DaKo, Copenhagen, Sweden). BrdU-positive cells were counted in high-magnification $(\times 400)$ fields, and the percentage of BrdU-positive cells in total crypts was scored by counting 100 intact crypts as described in the proliferative index and reported as the mean \pm standard deviation (SD). Eight mice were evaluated in each group.

\section{Isolation of intestinal crypt cells}

Intestinal crypt cells were isolated and cultured as described in our previous study ${ }^{52}$. Briefly, isolated small intestines were opened longitudinally, and washed with cold phosphate-buffered saline (PBS). The tissue was chopped into $\sim 5$ - $\mathrm{mm}$ pieces, and washed again with cold PBS. The tissue fragments were incubated in $2 \mathrm{mM}$ EDTA with PBS for $30 \mathrm{~min}$ on ice. Following removal of the EDTA medium, the tissue fragments were vigorously suspended using a $10-\mathrm{ml}$ pipette with cold PBS. This fraction was passed through a 70-mm cell strainer (BD Biosciences, Franklin Lakes, NJ, USA) to remove residual villous material. Isolated crypts were centrifuged at $150-200 \times g$ for $3 \mathrm{~min}$ to separate crypts from single cells. The final crypts were counted and pelleted. A total of 500 crypts were mixed with $50 \mu$ l of Matrigel (BD Bioscience) and plated in 24-well plates. After polymerization of Matrigel, $500 \mu \mathrm{l}$ of crypt culture medium (DMEM/F12 (Invitrogen)) containing growth factors $(10-50 \mathrm{ng} / \mathrm{ml}$ EGF (Peprotech)), $500 \mathrm{ng} / \mathrm{ml} \mathrm{R-spondin} 1$ and $100 \mathrm{ng} / \mathrm{ml}$ Noggin (Peprotech)) was added. Isolated crypts were incubated in culture medium for $45 \mathrm{~min}$ at $37^{\circ} \mathrm{C}$, following by trituration with a glass pipette. Crypt cells were passed through cell strainer with a pore size of $20 \mu \mathrm{m}$ and collected in culture medium.

\section{Total RNA extraction and real-time PCR}

Total RNA was extracted from IECs isolated from small intestines of mice using the RNAgents Total RNA Isolation System (Promega, Madison, WI, USA) according to the manufacturer's instructions. A total of $40 \mathrm{ng}$ of RNA was reverse-transcribed into cDNA using the miRNA Reverse Transcription kit (Applied Biosystems, Foster City, CA, USA). The TaqMan MicroRNA Assay (Qiagen, Hilden, Germany) was used for real-time PCR using sequence-specific primers for cDNA synthesis and Taqman probes for real-time PCR. The expression of miRNAs was normalized to that of the rnu19 gene. Thirty novel miRNAs chosen from the miRNA expression profile of mouse embryos ${ }^{25}$ were analyzed. Their sequences are described in Table 1. The all primer sequences of forward miRNAs, shared reverse miRNAs, and mRNAs were 
Table 1 Thirty miRNAs and their sequences.

\begin{tabular}{|c|c|}
\hline Name & Sequence \\
\hline mmu-miR-181b-1 & AACAUUCAUUGCUGUCGGUGGGU \\
\hline mmu-miR-423 & AGCUCGGUCUGAGGCCCCUCAGU \\
\hline mmu-miR-337 & UCAGCUCCUAUAUGAUGCCUUU \\
\hline mmu-miR-370 & GCCUGCUGGGGUGGAACCUGGU \\
\hline mmu-miR-379 & UGGUAGACUAUGGAACGUAGG \\
\hline mmu-miR-412 & UUCACCUGGUCCACUAGCCG \\
\hline mmu-miR-376b & AUCAUAGAGGAACAUCCACUU \\
\hline mmu-miR-153 & UUGCAUAGUCACAAAAGUGAUC \\
\hline mmu-miR-681 & CAGCCUCGCUGGCAGGCAGCU \\
\hline mmu-miR-27b & UUCACAGUGGCUAAGUUCUGC \\
\hline mmu-miR-195 & UAGCAGCACAGAAAUAUUGGC \\
\hline mmu-miR-711 & GGGACCCGGGGAGAGAUGUAAG \\
\hline mmu-miR-719 & AUCUCGGCUACAGAAAAAUGUU \\
\hline mmu-miR-16-1 & CCAGUAUUGACUGUGCUGCUGA \\
\hline mmu-miR-15a & UAGCAGCACAUAAUGGUUUGUG \\
\hline mmu-miR-33 & GUGCAUUGUAGUUGCAUUGCA \\
\hline mmu-miR-615 & UCCGAGCCUGGGUCUCCCUCUU \\
\hline mmu-miR-688 & UCGCAGGCGACUACUUAUUC \\
\hline mmu-miR-690 & AAAGGCUAGGCUCACAACCAAA \\
\hline mmu-miR-691 & AUUCCUGAAGAGAGGCAGAAAA \\
\hline mmu-miR-693 & CAGCCACAUCCGAAAGUUUUC \\
\hline mmu-miR-301 & CAGUGCAAUAGUAUUGUCAAAG \\
\hline mmu-miR-133a-3 & UUUGGUCCCCUUCAACCAGCUG \\
\hline mmu-miR-345 & GCUGACCCCUAGUCCAGUGCUU \\
\hline mmu-miR-145 & GUCCAGUUUUCCCAGGAAUCCCU \\
\hline mmu-miR-143 & UGAGAUGAAGCACUGUAGCUC \\
\hline mmu-miR-146b & UGAGAACUGAAUUCCAUAGGCU \\
\hline mmu-miR-669b & AGUUUUGUGUGCAUGUGCAUGU \\
\hline mmu-miR-695 & AGAUUGGGCAUAGGUGACUGAA \\
\hline mmu-miR-674-5p & GCACUGAGAUGGGAGUGGUGUA \\
\hline
\end{tabular}

The English in this document has been checked by at least two professional editors, both native speakers of English. For a certificate, please see: http://www. textcheck.com/certificate/TnOlxO.

purchased from Guangzhou RiboBio Co.; Ltd (13-14/F, Innovation Building C3, 182 Kexue Avenue, Science Park, Guangzhou 510663, China). The primer sequences of ten changed miRNAs were followed as below: miRNA-681: "CAGCCTCGCTGGCAGGCAGCT", miRNA-719: Forward "ATCTCGGCTACAGAAAAATGTT", miRNA-711: Forward "GGGACCCGGGGAGAGATGTAAG", miRNA33: "GTGCATTGTAGTTGCATTGCA", miRNA-16-1: "TAGCAGCACGTAAATATTGGCG", miRNA-345: "GC
TGACCCCTAGTCCAGTGCTT", miRNA-674-5p: "GCA CTGAGATGGGAGTGGTGTA", miRNA-301: "GCTC TGACTTTATTGCACTACT", miRNA-143: "GGTGCA GTGCTGCATCTCTGG", miRNA-695: "AGATTGGGC ATAGGTGACTGAA". HIF-1 $\alpha$ : Forward "TCTCGGCG AAGCAAAGAGTC", Reverse "AGCCATCTAGGGCTT TCAGATAA".

\section{Cell culture, treatments, and proliferative index}

The human embryonic intestinal mucosa-derived cell line CCC-HIE-2, Hypoxia inducible factor (HIF)- $1 \alpha^{+/+}$ and HIF- $1 \alpha^{-/-}$mouse embryonic fibroblasts (MEFs) were originally obtained from the National Infrastructure of Cell Line Resource (Chinese Academy of Medical Sciences). The rat small intestine cell line IEC-6 was obtained from the American Type Culture Collection (ATCC; Manassas, VA, USA). CCC-HIE-2 and IEC-6 cells were cultured in complete medium consisting of Dulbecco's modified Eagle medium (DMEM) or DMEM/F12 (Thermo Fisher Scientific, Waltham, MA, USA), respectively, supplemented with $10 \%$ fetal bovine serum at $37^{\circ} \mathrm{C}$ in a $\mathrm{CO}_{2}$ incubator.

Anti-miR-674-5p oligonucleotide (100 nmol/L) and its scrambled negative control (Ambion) were used in in vitro experiments and transfected into CCC-HIE-2 cells, IEC-6 cells, or MEFs for $24 \mathrm{~h}$ prior to stimulation with LPS $(100 \mathrm{ng} / \mathrm{mL})$ for $24 \mathrm{~h}$.

XBP-1, activating transcription factor (AFT)-6, or protein kinase R-like endoplasmic reticulum kinase (PERK; $100 \mathrm{nmol} / \mathrm{L}$ ) (Thermo Fisher Scientific) or their scrambled negative controls were used in in vitro experiments and transfected into IEC- 6 cells for $24 \mathrm{~h}$ prior to stimulation with LPS $(100 \mathrm{ng} / \mathrm{mL})$ for $24 \mathrm{~h}$.

For BrdU staining, BrdU was co-cultured with CCCHIE- 2 or IEC-6 cells for $4 \mathrm{~h}$ before harvesting. Staining was performed according a standard protocol with antiBrdU antibody (1:100 in 5\% BSA; Sigma-Aldrich) and secondary antibody (Santa Cruz Biotechnology, Inc.), and color was developed using a DAB Kit (DaKo). The proliferative index was determined by dividing the number of BrdU-positive cells by the total number of cells in at least 20 randomly selected fields ( $\times 200$ magnification). Three independent experiments were performed.

\section{Bacterial culturing}

For CFU analysis of E. coli in mesenteric lymph nodes (MLNs), we harvested and homogenized MLNs in sterile PBS, which were serially diluted and plated followed by incubation at $37^{\circ} \mathrm{C}$ for $24 \mathrm{~h}$.

\section{Northern blot analysis}

The sequences for probing miR-647-5p in northern blot were "TACACCACTCCCATCTCAGTGC" and internal control: "CACGGGAAGTCTGGGCTAAGAGACA", which 
were purchased from Shanghai Generay Biotech Co., Ltd (13-14 Building, No.5398 Shenzhuan Rd, Songjiang District, Shanghai, 201619 China). Northern blot analysis of miRNAs was conducted according to the manufacturer's instruction. Briefly, $10 \mu \mathrm{g}$ of total RNA isolated using the Ambion RNA extraction kit (Applied Biosystems) was resolved using a 15\% acrylamide-bisacrylamide gel (19:1) containing $7 \mathrm{M}$ urea in Tris-borate-EDTA buffer. Following transfer to a Hybond membrane (Amersham, Uppsala, Sweden) and ultraviolet crosslinking, the membrane was incubated with the radiolabeled hybridization probe in Ultra-Hyb-oligo hybridization buffer (Ambion). The membrane was then washed extensively before exposure to X-ray film at $-70^{\circ} \mathrm{C}$.

\section{Chromatin immunoprecipitation}

Chromatin immunoprecipitation (ChIP) analysis of HIF- $1 \alpha$ binding to the miR-674-5p promoter was performed using an assay kit (R\&D Systems, Minneapolis, MN, USA) according to the manufacturer's instructions. The primer sequences of the miR-674-5p promoter were: Forward "GCTACCACATTTCATCTGACTAGAG". Reverse "AGCAAGCACTTGATTTCACATAAC", which was purchased from Shanghai Generay Biotech Co., Ltd (13-14 Building, No.5398 Shenzhuan Rd, Songjiang District, Shanghai, 201619 China). Briefly, following fixation with formaldehyde, cell lysates were collected and sonicated to shear chromatin. The samples were then centrifuged to collect the supernatant for immunoprecipitation with anti-HIF- $1 \alpha$ antibody. After several washes, the resulting immunoprecipitates were subjected to PCR analysis using specific primers.

\section{Microarray experiment}

The mixture, containing Lipofectamine (Invitrogen, Carlsbad, CA, USA) and miR-674-5p or scambled dissolved in Optimal (Invitrogen), was added to cells at $80 \%$ confluence, and $24 \mathrm{~h}$ after interference, and harvested. PCR was used to test successful transfection into cells.

The Agilent SurePrint G3 Human Gene Expression $8 \times 60 \mathrm{~K}$ Array was designed with eight identical arrays per slide, with each array containing probes interrogating 27,958 Entrez Gene RNAs. The array also contained 1280 Agilent control probes. The four scrambled samples were human IECs (FHC cells) tranfected with the scramble sequence. The six miR-674-5p samples were human IECs (FHC cells) tranfected with the miR-674-5p. Total RNA from each sample was isolated using TRIzol reagent according to the manufacturer's instructions (Invitrogen, Carlsbad, CA, USA) and was further purified using the mirVana miRNA Isolation Kit (Ambion) according to the manufacturer's instructions. The purity and concentration of RNA was tested with OD260/280 readings using a spectrophotometer (NanoDrop ND-1000). cDNA labeled with the fluorescent dye Cy3-dCTP was constructed by
Eberwine's linear RNA amplification method and subsequent enzymatic reaction. The procedure was optimized using the CapitalBio cRNA Amplification and Labeling Kit (CapitalBio, Beijing, China) for producing high yields of labeled cDNA. DNA polymerase and RNase $\mathrm{H}$ were employed to synthesize double-stranded cDNA (dsDNA) and the dsDNA products were purified using a PCR NucleoSpin Extract II Kit and eluted with $30 \mu \mathrm{L}$ of elution buffer. The eluted dsDNA products were evaporated to $16 \mu \mathrm{L}$ and subjected to in vitro transcription reactions of $40 \mu \mathrm{L}$ at $37^{\circ} \mathrm{C}$ for $14 \mathrm{~h}$ using a T7 Enzyme Mix. A Klenow enzyme labeling strategy was used following reverse transcription using CbcScriptII reverse transcriptase. Array hybridization was carried out in a hybridization oven (Agilent Technologies, Santa Clara, CA, USA) overnight at a rotation speed of $20 \mathrm{rpm}$ at $42{ }^{\circ} \mathrm{C}$ and washed with two consecutive solutions. Data summarization, normalization, and quality control of the array data were performed using GeneSpring software V12 (Agilent Technologies). To screen the differentially expressed genes, threshold values of $\geq 1.5$ - and $\leq 1.5$-fold change and a Benjamini-Hochberg corrected $P$ value of 0.05 were used. The data were $\log 2$ transformed and median centered by genes using the Adjust Data function of CLUSTER 3.0 software and then further analyzed with hierarchical clustering with average linkage. Finally, tree visualization was presented using Java Treeview software (Stanford University School of Medicine, Stanford, CA, USA). Data from this study are available from the National Center for Biotechnology Information under GEO accession number GSE67764.

\section{Plasmid constructs and luciferase reporter assay}

The human 3 -UTR of the XBP-1 gene was amplified by PCR using the primers XBP-1-3'-UTR-Forward (5'GTAAGCAACGGGAACA-3') and XBP-1-3'-UTRReverse (5'-AAATGGAGAAAGCACCT- $3^{\prime}$ ) and cloned into the $X b a \mathrm{I} / \mathrm{Xba \textrm {I }}$ site of the pGL3 control vector (Promega) to generate the vector pGL3-XBP-1. For the luciferase reporter assay, CCC-HIE-2 cells were cultured in 96-well plates and transfected with pGL3-XBP-1+ miR-674-5p mimic, pGL3-XBP-1, pGL3-control + miR674-5p mimic, or pGL3-control using Lipofectamine 2000 (Invitrogen). At $48 \mathrm{~h}$ after transfection, cells were collected, washed with PBS, and analyzed with a dualluciferase reporter assay system (Promega) according to the manufacturer's instructions with a Lumat LB 9507 luminometer (Berthold, Nashua, NH, USA).

\section{Tumor necrosis factor- $\alpha$ and interleukin- 6 assays}

The concentrations of TNF- $\alpha$ and IL- 6 in small intestinal mucosa of mice were measured using a commercial kit (eBioscience, San Diego, CA, USA) according to the manufacturer's instructions. After the stop solution was 
added, the plates were read at $450 \mathrm{~nm}$ ( $570 \mathrm{~nm}$ correction) on a MicroPlate Reader (BioTek, Seattle, WA, USA). The results are expressed as pg TNF- $\alpha / \mathrm{mg}$ protein and ng IL$6 / \mathrm{mg}$ protein.

\section{Western blotting and antibodies}

Total protein $(50 \mu \mathrm{g})$ of small IECs was denatured in sample buffer containing sodium dodecyl sulfate (SDS) and $\beta$-mercaptoethanol, separated using 4-20\% gradient SDS-polyacrylamide gel electrophoresis, and transferred onto nitrocellulose membranes. Nonspecific binding sites of the membranes were blocked using defatted milk protein. The relative amount of primary antibody was detected with peroxidase-conjugated secondary antibody. Densitometry was used to quantify protein abundance. Similar procedures were performed with antibodies against XBP-1, GRP78, and ATF-6 (Sigma-Aldrich); cleaved caspase- 3 and cleaved caspase-12, sXBP-1 (Cell Signaling Technology, Danvers, MA, USA); and HIF-1 $\alpha$, eukaryotic initiation factor (eIF)-2 $\alpha$, phosphorylated eIF2 $\alpha$ (p-eIF2 $\alpha$ ), Ki67 (Abcam, Cambridge, UK).

\section{Statistical analysis}

All experiments were performed at least in triplicate. Data are expressed as mean \pm SD. Six mice were used in each group. Randomization was used in each independent experiment. Statistical significance was analyzed with the one-way or two-way ANOVA test for gene and protein expression, comparing miRNAs expression, cellular proliferation, luciferase activity, inflammatory factors, BrdU positive counts, and positive rate differences between two groups. The survival data were analyzed by log-rank test using GraphPad Prism software. Differences were considered significant if the probability of the difference occurring by chance was $<0.05(P<0.05)$.

\section{Acknowledgements}

We thank Prof. Dr. Lijuan Jiang and Dr. Jinli Liao at the Sun Yat-sen University in China for counting proliferation indices. We thank other members of our laboratories for helpful discussions and comments. The study was supported by Grants-in-Aid from Grants-in-Aid from Zhihao Liu with National Natural Scientific Foundation of China (81602660), Guangdong Natural Science Foundation (2016A030310159), and Yan Xiong with the Fundamental Research Funds for the Central Universities-Training Funds for Young Scholars of Sun Yat-sen University (11ykpy14) from China. The study was also financially supported by Zhen Yang's grants with National Natural Scientific Foundation of China (81670220), the project of science and technology program of Guangzhou City (201803010008) and the international scientific and technological cooperation project of Guangzhou Economic and Technological Development Zone (2017GH13).

\footnotetext{
Author details

${ }^{1}$ Division of Emergency Medicine, Department of General Internal Medicine, Department of Emergency Intensive Care Unit, The First Affiliated Hospital of Sun Yat-sen University, No.58, Zhongshan 2nd Road, 510080 Guangzhou, China. ${ }^{2}$ Department of Gastroenterology, The Third Affiliated Hospital of Sun Yat-Sen University, No.600, Tianhe Road, 510360 Guangzhou, China. ${ }^{3}$ Department of Gastrointestinal Surgery, The First Affiliated Hospital of Sun Yat-sen University, No.58, Zhongshan 2nd Road, 510080 Guangzhou, China.
}

${ }^{4}$ Department of Critical Care Medicine, The Sixth Affiliated Hospital of Sun Yatsen University, No.26, YuanCunErHeng Road, 510655 Guangzhou, China

\section{Author contributions}

Z.L., J.J. and W.D. contributed equally to this work; Z.L., Z.Y. and Y.X. designed the research; Z.L., J.J., W.D., H.W. and X.Z. performed the research; Z.L., Z.Y. and Y.X. analyzed the data; Z.L., Z.Y. and Y.X. analyzed contributed reagents/ materials/analysis tools; Z.L. and Y.X. wrote the paper.

\section{Conflict of interest}

The authors declare that they have no conflict of interest.

\section{Publisher's note}

Springer Nature remains neutral with regard to jurisdictional claims in published maps and institutional affiliations.

The online version of this article (https://doi.org/10.1038/s41420-020-0280-5) contains supplementary material, which is available to authorized users.

Received: 18 March 2020 Revised: 30 April 2020 Accepted: 19 May 2020 Published online: 04 June 2020

\section{References}

1. Rhee, $C$. et al. CDC Prevention Epicenter Program. Incidence and trends of endotoxemia in US hospital using clinical vs claims data, 2009-2014. JAMA 318, 1241-1249 (2017).

2. Vincent, J. L., Opal, S. M., Marshall, J. C. \& Tracey, K. J. Endotoxemia definitions: time for change. Lancet 381, 774-775 (2013).

3. Clark, J. A. \& Coopersmith, C. M. Intestinal crosstalk: a new paradigm for understanding the gut as the "motor" of critical illness. Shock 28, 384-393 (2007).

4. Hassoun, H. T. et al. Post-injury multiple organ failure: the role of the gut. Shock 15, 1-10 (2001)

5. Coopersmith, C. M. et al. Overexpression of $\mathrm{BCl}-2$ in the intestinal epithelium improves survival in endotoxemia mice. Crit. Care Med. 30, 195-201 (2002).

6. Coopersmith, C. M. et al. Inhibition of intestinal epithelial apoptosis and survival in a murine model of pneumonia-induced endotoxemia. JAMA 287, 1716-1721 (2002).

7. Dominguez, J. A. et al. Inhibition oflKKßin enterocytes exacerbates endotoxemia-induced intestinal injury andworsens mortality. Crit. Care Med. 41, e275-e285 (2013).

8. Nullens, S. et al. Effect of GTS-21, an alpha7 nicotinic acetylcholine receptor agonist, on CLP-induced inflammatory, gastrointestinal motility, and colonic permeability changes in mice. Shock 45, 450-459 (2016).

9. Li, Y. et al. Hydrogen gas alleviates the intestinal injury caused by severe endotoxemia in mice by increasing the expression of heme oxygenase-1. Shock 44, 90-98 (2015).

10. Hall, P. A., Coates, P. J., Ansari, B. \& Hopwood, D. Regulation of cell number in the mammalian gastrointestinal tract: the importance of apoptosis. J. Cell Sci. 107, 3569-3577 (1994).

11. Buchheister, S. et al. CD14 plays a protective role in experimental inflammatory bowel disease by enhancing intestinal barrier function. Am. J. Pathol. 187, 1106-1120 (2017)

12. Vandenbroucke, R. E. et al. Matrix metalloproteinase 13 modulates intestinal epithelial barrier integrity in inflammatory diseases by activating TNF. EMBO Mol. Med. 5, 1000-1016 (2013).

13. Khailova, L., Frank, D. N., Dominguez, J. A. \& Wischmeyer, P. E. Probiotic administration reduces mortality and improvesintestinal epithelial homeostasis in experimental endotoxemia. Anesthesiology 119, 166-177 (2013).

14. Mendell, J. T. \& Olson, E. N. MicroRNAs in stress signaling and human disease. Cell 148, 1172-1187 (2012).

15. Eulalio, A., Huntzinger, E. \& Izaurralde, E. Getting to the root of miRNAmediated gene silencing. Cell 132, 9-14 (2008).

16. Xiao, L. \& Wang, J. Y. RNA-binding proteins and microRNAs in gastrointestinal epithelial homeostasis and diseases. Curr. Opin. Pharmacol. 19, 46-53 (2014).

17. Xiao, L. et al. Regulation of cyclin-dependent kinase 4 translation through CUG-binding protein 1 and microRNA-222 by polyamines. Mol. Biol. Cell 22, 3055-3069 (2011). 
18. Yang, H., Rao, J. N. \& Wang, J. Y. Posttranscriptional regulation of intestinal epithelial tight junction barrier by RNA-binding proteins and microRNAs. Tissue Barriers 2, e28320 (2014).

19. Cao, S. et al. Inhibition of Smurf2 translation by miR-322/503 modulates TGF- $\beta$ / Smad2 signaling and intestinal epithelial homeostasis. Mol. Biol. Cell 25, 1234-1243 (2014).

20. Cui, Y. H. et al. miR-503 represses CUG-binding protein 1 translation by recruiting CUGBP1 mRNA to processing bodies. Mol. Biol. Cell 23, 151-162 (2012).

21. Bakirtzi, K. et al. Neurotensin signaling activates microRNAs-21 and -155 and Akt, promotes tumor growth in mice, and is increased in human colon tumors. Gastroenterology 141, 1749-1761 (2011).

22. Zhuang, R. et al. miR-195 competes with HuR to modulate stim1 mRNA stability and regulate cell migration. Nucleic Acids Res. 41, 7905-7919 (2013).

23. Ye, D., Guo, S., Al-Sadi, R. \& Ma, T. Y. MicroRNA regulation of intestinal epithelia tight junction permeability. Gastroenterology 141, 1323-1333 (2011).

24. Ouyang, M. et al. Modulation by miR-29b of intestinal epithelium homoeostasis through the repression of menin translation. Biochem. J. 465, 315-323 (2015).

25. Mineno, J. et al. The expression profile of microRNAs in mouse embryos. Nucleic Acids Res. 34, 1765-1771 (2006).

26. Bakirtzi, K. et al. Neurotensin promotes the development of colitis and intestinal angiogenesis via Hif-1a-miR-210 signaling. J. Immunol. 196 4311-4321 (2016)

27. Akhtar, S. et al. Endothelial hypoxia-inducible factor-1a promotes atherosclerosis and monocyte recruitment by upregulating microRNA-19a. Hypertension 66, 1220-1226 (2015).

28. Csak, T. et al. microRNA-122 regulates hypoxia-inducible factor-1 and vimentin in hepatocytes and correlates with fibrosis in diet-induced steatohepatitis. Liver Int. 35, 532-541 (2015).

29. Hetz, C. The unfolded protein response: controlling cell fate decisions under ER stress and beyond. Nat. Rev. Mol. Cell Biol. 13, 89-102 (2012).

30. Niederreiter, L. et al. ER stress transcription factor Xbp1 suppresses intestinal tumorigenesis and directs intestinal stem cells. J. Exp. Med. 210, 2041-2056 (2013).

31. Zhang, F. et al. MicroRNA-146a Induced by Hypoxia Promotes Chondrocyte Autophagy through Bcl-2. Cell Physiol. Biochem. 37, 1442-1453 (2015).

32. Ling, S. et al. MicroRNA-dependent cross-talk between VEGF and HIF1a in the diabetic retina. Cell Signal 25, 2840-2847 (2013).

33. Fang, $Y$. et al. miR-29c is downregulated in renal interstitial fibrosis in humans and rats and restored by HIF-a activation. Am. J. Physiol. Ren. Physiol. 304 F1274-F1282 (2013)

34. Bhatt, $K$. et al. MicroRNA-687 induced by hypoxia-inducible factor-1 targetsphosphatase and tensin homolog in renal ischemia-reperfusion injury. J. Am. Soc. Nephrol. 26, 1588-1596 (2015).
35. Wei, Q. et al. MicroRNA-489 induction by hypoxia-inducible factor-1 protects against ischemic kidney injury. J. Am. Soc. Nephrol. 27, 2784-2796 (2016).

36. Huang, C. X. et al. Zebrafish let-7b acts downstream of hypoxia-inducible factor-1a to assist in hypoxia-mediated cell proliferation and cell cycle regulation. Life Sci. 171, 21-29 (2017).

37. Zhang, C., Tian, W., Meng, L., Qu, L. \& Shou, C. PRL-3 promotes gastric cancer migration and invasion through a NF-KB-HIF-1a-miR-210 axis. J. Mol. Med. 94, 401-415 (2016).

38. Glimcher, L. H. XBP1: the last two decades. Ann. Rheum. Dis. Suppl 1, i67-i71 (2010).

39. Kaser, A. et al. XBP1 links ER stress to intestinal inflammation and confersgenetic risk for human inflammatory bowel disease. Cell 134, 743-756 (2008).

40. Kaser, A. \& Blumberg, R. S. Endoplasmic reticulum stress and intestinal inflammation. Mucosal Immunol. 3, 11-16 (2010).

41. Ma, A. Unresolved ER stress inflames the intestine. Cell 134, 724-725 (2008).

42. Zeng, L. et al. Vascular endothelial cell growth-activated XBP1 splicing inendothelial cells is crucial for angiogenesis. Circulation 127, 1712-1722 (2013).

43. Zeng, L. et al. XBP 1-deficiency abrogates neointimal lesion of injured vessels viacross talk with the PDGF signaling. Arterioscler. Thromb. Vasc. Biol. 35 2134-2144 (2015).

44. Xu, T. et al. The IRE1a XBP1 pathway regulates metabolic stressinducedcompensatory proliferation of pancreatic $\beta$-cells. Cell Res. 24 1137-1140 (2014).

45. Hess, D. A. et al. Extensive pancreas regeneration following acinar-specific disruptionof Xbp1 in mice. Gastroenterology 141, 1463-1472 (2011).

46. Argemí, J. et al. X-box binding protein 1 regulates unfolded protein, acutephase, and DNA damage responses during regeneration of mouse liver. Gastroenterology 152, 1203-1216 (2017).

47. Xia, T. et al. XBP1 induces MMP-9 expression to promote proliferation andinvasion in human esophageal squamous cell carcinoma. Am. J. Cancer Res. 6, 2031-2040 (2016).

48. Chen, $\mathrm{X}$. et al. XBP1 promotes triple-negative breast cancer by controlling the HIFla pathway. Nature 508, 103-107 (2014).

49. Wang, L., Ryoo, H. D., Qi, Y. \& Jasper, H. PERK limits drosophila lifespan by promoting intestinal stem cell proliferation in response to ER stress. PLOS Genet. 11, e1005220 (2015).

50. Wahlquist, C. et al. Inhibition of miR-25 improves cardiac contractility in the failing heart. Nature 508, 531-535 (2014).

51. Chiu, C. J., McArdle, A. H., Brown, R., Scott, H. J. \& Gurd, F. N. Intestinal mucosal lesion in low-flow states. I. A morphological, hemodynamic, and metabolic reappraisal. Arch. Surg. 101, 478-483 (1970).

52. Toshiro Sato et al. Single Lgr5 stem cells build crypt-villus structures in vitro without a mesenchymal niche. Nature 459, 262-265 (2009). 